\title{
Gastrointestinal lymphoma in childhood
}

C. L. BERRY AND JEAN W. KEELING

From the Department of Morbid Anatomy, Institute of Child Health and Hospital for Sick Children, Great Ormond Street, London

Primary neoplasms of the gastrointestinal tract are infrequent in childhood and comprise less than $1 \%$ of tumours seen in this age group. The majority of the recorded cases are tumours of the reticuloendothelial system. Several centres have published small series describing intraabdominal lymphosarcomata alone or as part of a review of malignant lymphomata in childhood (Bailey, Burgert, and Dahlin, 1961; Jones and Klingberg, 1963; Rosenberg, Diamond, Dargeon, and Craver, 1958; Sullivan, 1962; Cutler, Stark, and Scott, 1945; Charache, 1956; Maxwell, 1954; Mestel, 1959).

We present here a review of 13 primary malignant gastrointestinal lymphosarcomata, with an assessment of their course, response to therapy, and histological appearance.

\section{Materials and Methods}

During the 10 -year period $1960-69,15$ primary tumours of the gastrointestinal tract have been seen in this hospital (upper age limit is approximately 13 years). Two were teratomata arising in the gastric wall and have been reported elsewhere (Atwell, Claireaux, and Nixon, 1967; Berry, Keeling, and Hilton, 1969). From the remaining 13 cases, sections of the surgical specimens were stained with haematoxylin and eosin, haematoxylin-van Gieson, Gordon and Received for publication 2 December 1969.
Sweet's reticulin stain, and the Unna-Pappenheim techniques. Necropsy material was available from one case (case 2).

\section{Results}

The clinical details, age at presentation, sex, duration of symptoms, operative findings, sub-? sequent treatment, and progress are shown in Table I.

\section{PATHOLOGICAL FINDINGS}

Typical macroscopic appearances are seen in $>$ Figs. 1 and 2 (case 5) and Figs. 3 and 4 (case 7). Microscopic findings are summarized in Table ${ }_{\%}$ II. Ten tumours are lymphoblastic lymphosarcomata and are composed of closely packed ${ }_{N}$ round cells having prominent nuclei with little $\omega$ cytoplasm (Fig. 5). Five of these tumours contain large phagocytic reticular cells giving a 'starry'o sky' appearance and in three instances other ${ }_{\mathscr{\Phi}}$ cytological characteristics of the 'Burkitt' type - $^{-}$ of lymphoma (ill-defined cytoplasmic border, $\stackrel{0}{-}$ small cytoplasmic vacuoles, prominent nucleoli, $\frac{\stackrel{\oplus}{\mathbb{D}}}{\mathbb{0}}$ frequent mitoses, occasional pyroninophilia) are $\stackrel{\odot}{\odot}$ present (Fig. 6). Involvement of the muscle coats $\varrho$ of the bowel wall leads to the appearance of altered muscle cells within the tumour in someo instances.

Three tumours are considered to be reticulum 


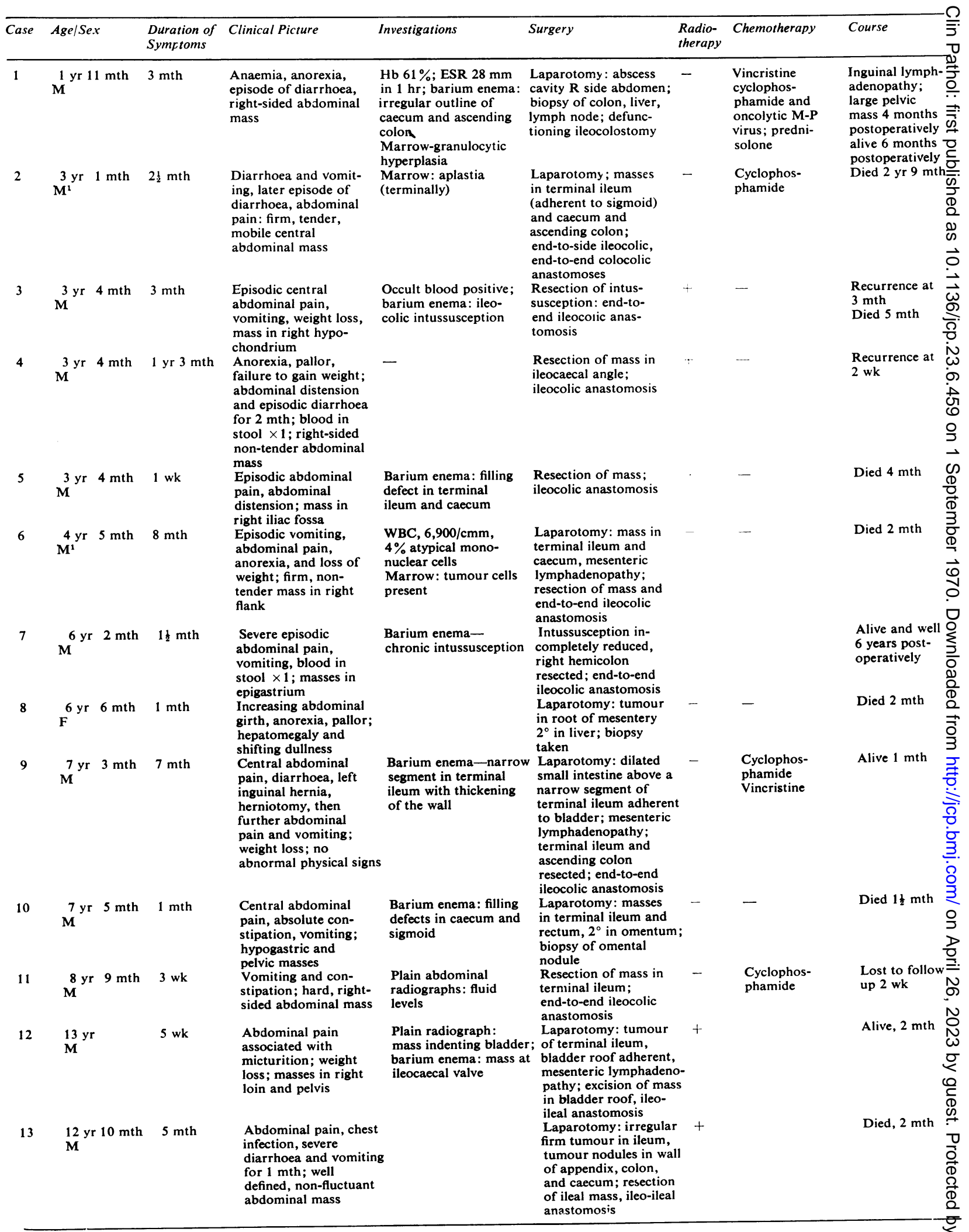




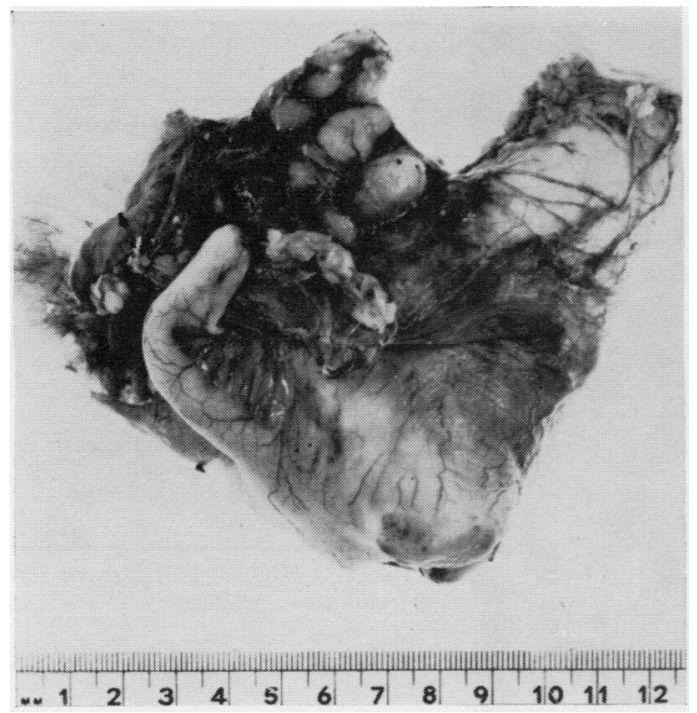

Fig. 1 Case 5: white nodules can be seen through the serosa distorting the normal intestinal profile. Enlarged lymph nodes are seen in the mesentery.

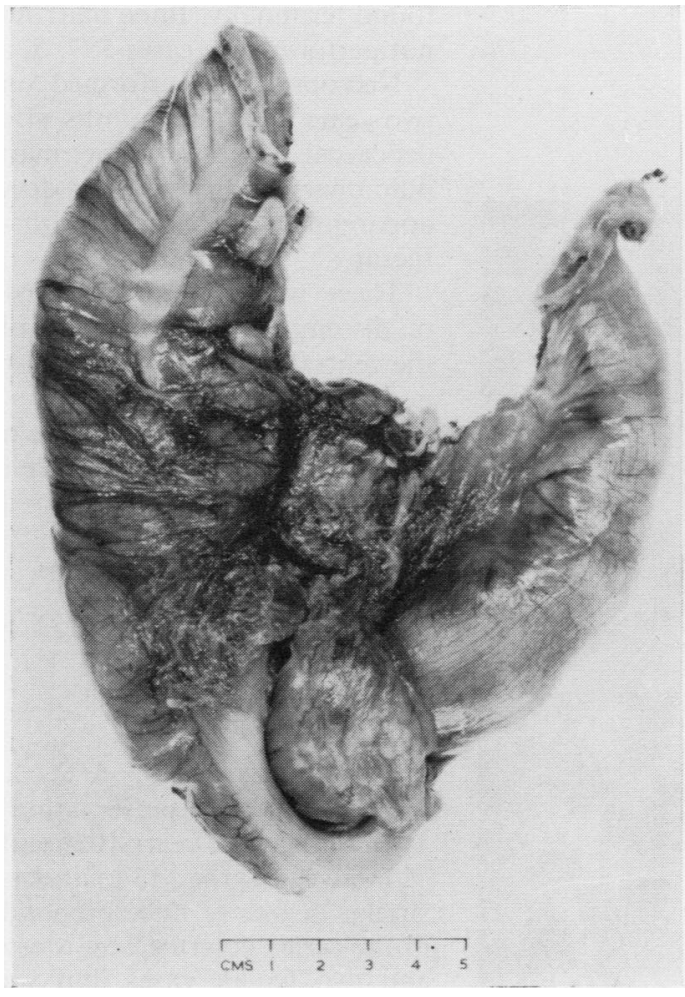

Fig. 3 Case 7: the terminal ileum (right) and caecum are diffusely thickened.

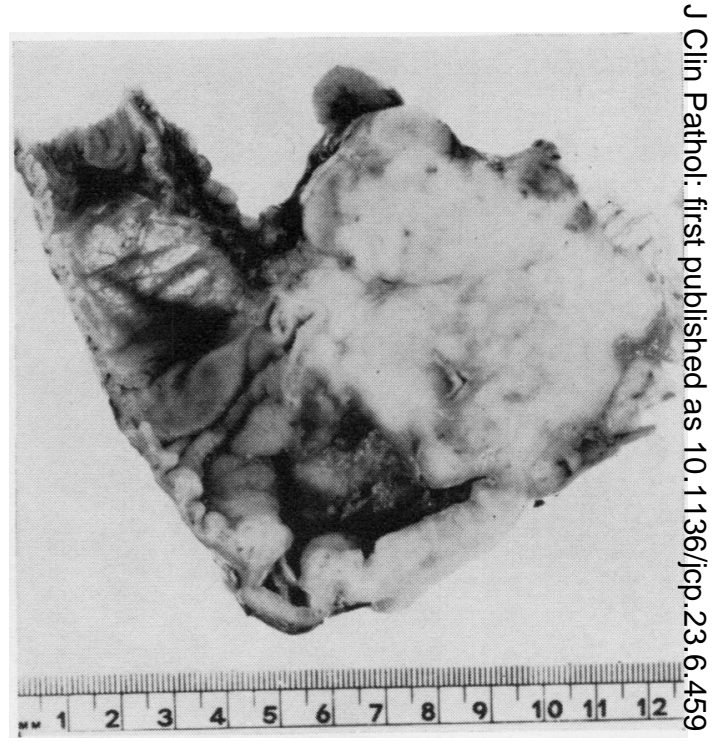

Fig. 2 Case 5: Hemisection shows a homogeneous white tumour involving the bowel wall with ulceration of the overlying mucosa and affecting local lymph nodes by direct extension.

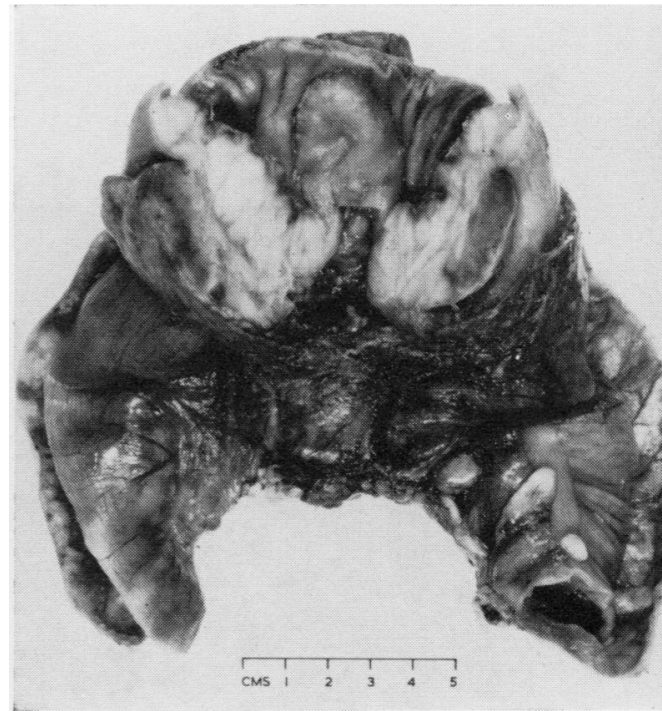

Fig. 4 Case 7: Hemisection shows an area of white tumour within the bowel wall at the apex of the intussusception. 


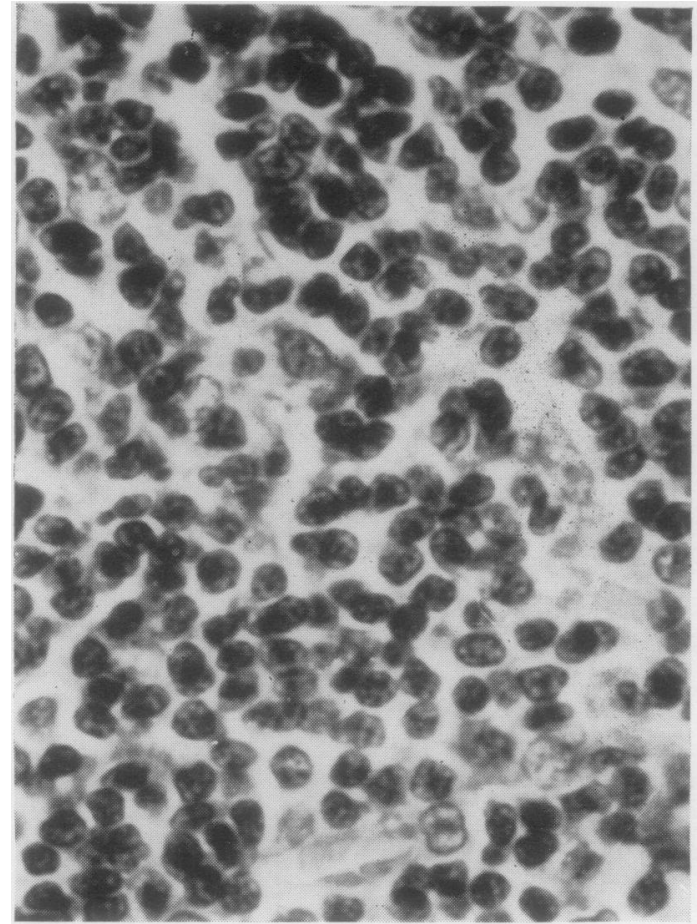

Fig. 5 Typical appearance of lymphosarcoma (haematoxylin and eosin $\times 500$ ).

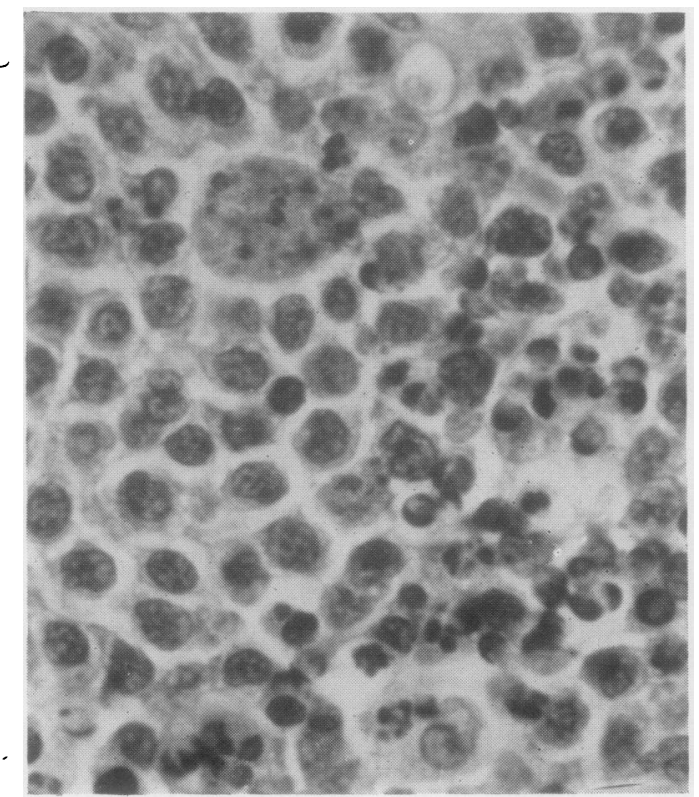

Fig. 6 Lymphosarcoma with histiocytes containing nuclear debris scattered in the tumour mass (haematoxylin and eosin $\times 540$ ).

\begin{tabular}{|c|c|c|}
\hline Case & Site & $\begin{array}{l}\text { Histological } \\
\text { Appearance }\end{array}$ \\
\hline 1 & $\begin{array}{l}\text { Caecum and ascending colon, } \\
2^{\circ} \text { liver }\end{array}$ & Lymphosarcoma \\
\hline 2 & Terminal ileum and caecum & Reticulum cell sarcoms \\
\hline $\begin{array}{l}3 \\
4\end{array}$ & Terminal ileum and caecum & $\begin{array}{l}\text { Lymphosarcoma }^{1} \\
\text { Lymphosarcoma }^{1}\end{array}$ \\
\hline 5 & $\begin{array}{l}\text { Terminal ileum and caecum, } 2^{\circ} \\
\text { mesenteric nodes }\end{array}$ & Lymphosarcoma ${ }^{1}$ \\
\hline 6 & $\begin{array}{l}\text { Terminal ileum, caecum, } \\
\text { ascending colon }\end{array}$ & Reticulum cell sarcom $\frac{\overline{\overline{0}}}{\frac{\bar{D}}{7}}$ \\
\hline 7 & Terminal ileum and caecum & Lymphosarcoma \\
\hline 8 & Root of mesentery, liver $2^{\circ}$ & Lymphosarcoma \\
\hline 9 & Terminal ileum & Lymphosarcoma \\
\hline 10 & Ileum, rectum, omental $2^{\circ}$ & Lymphosarcoma ${ }^{1}$ \\
\hline 11 & Terminal ileum and caecum & Lymphosarcoma $^{1}$ \\
\hline 12 & Ileum $2^{\circ}$, bladder vault & Reticulum cell sarcom \\
\hline 13 & $\begin{array}{l}\text { Ileum, nodules in caecum and } \\
\text { colon, appendix }\end{array}$ & Lymphosarcoma $^{1}$ \\
\hline
\end{tabular}

Table II Histology of present series

${ }^{1}$ Burkitt-like morphology

cell sarcomas, and are composed of pleomorphio reticulin cells; binucleate cells are seen. Reticulin fibres are seen between cells and thicker cons densations of reticulin divide cell masses.

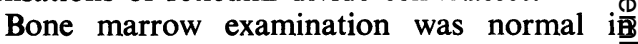
cases $3,4,9,11,12$, and 13 . The narrow aspirato in case 1 showed granulocytic hyperplasia but. no tumour infiltration. Appearances were withif normal limits in case 2 initially but terminal aplasia was found. In case 6 the tumour cells werg found terminally. Bone marrow examination was not performed in cases $5,7,8$, and 10 .

Necropsy was performed on case 2 ; he dief two years and nine months after resection of a ileocaecal tumour. Bone marrow aplasia an pulmonary fibrosis had developed and was apparently associated with cytotoxic drug therapy.

There was cultural and histological evidences of disseminated moniliasis with involvement $\frac{\text { of }}{}$ the central nervous system. Residual tumour was not found.

Tumour had involved bone marrow terminall in case 6 , with the appearance of tumour cells in the blood. Metastases occurred in cases 1, 3, $\frac{2}{2}$ 8,10 , and 12. Transcoelomic spread of tumout to other abdominal viscera was probable in case 13.

\section{Discussion}

The age range at presentation was from 1 yeag 11 months to 12 years 10 months in our series. ?

Twelve of the 13 patients were male; $\mathbb{P}$ similar degree of male preponderance was notef in the series described by Mestel (1959), 11 male and two female cases, but was less marked i8 other studies. Bailey et al (1961) found a male-top female ratio of $3 \cdot 4: 1$, and Jones and Klingbers (1963) had a male-to-female ratio of $2 \cdot 6: 1$.

The 13 tumours constitute $0.6 \%$ of all tumours 
seen at this hospital since 1957 (excluding leukaemia) and $37 \%$ of the lymphomata.

The presence of Burkitt-like morphology was not associated with a better prognosis and the phagocytic activity of histiocytes included in the tumour does not appear to be evidence of an effective host response to the tumour.

Two of the cases were brothers (cases 2 and 6): the familial tendency to develop lymphomata has been discussed elsewhere (Rigby, Rosenlof, Pratt, and Lemon, 1966) and will not be considered further here.

Abdominal pain and distension were the most frequent presenting symptoms, as in most series of both adult and childhood age groups (see Mestel, 1959, for bibliography).

Investigation showed no distinctive features, and in general findings were those of intestinal obstruction and intussusception.

Primary treatment was surgical and was designed to achieve complete resection (cases 2, 3, $4,5,6,7,9,11$, and 12 ) or palliation (cases 1 and 13). In cases 8 and 10 biopsy only was performed and no further treatment was given. Cases 3, 4, 5, and 13 were treated by radiotherapy and cases 1 , $2,9,11$, and 12 by cytotoxic drugs in addition. Four patients are alive but two have been diagnosed only in the last few months. Of the remaining two, case 1 is alive with evidence of extensive disease after six months. There is one long-term survivor (case 7) who is free of disease six years after radical surgery alone. These dismal results compare with those found in other series (Charache, 1956; Mestel, 1959). Bailey et al (1961) have achieved some success with surgery and radiotherapy in a small series (three long-term survivors from nine cases).

These cases presented over a period of 10 years, and policy regarding chemotherapy and radiotherapy probably reflects common usage at that time, except in cases 8 and 10 where extensive metastatic spread was present at laparotomy and specific antitumour therapy was withheld. Bone marrow examination was not performed in all cases, and the use of antitumour therapy was not based on the findings in the blood.
In general this is a tumour with an exceedingly $\frac{O}{5}$ grave prognosis. Its relative infrequency and the $T$ varied methods of treatment employed prevent a $\stackrel{0}{F}$ rational assessment of the efficiency of various therapeutic regimes but it seems likely that radical $\overrightarrow{\overrightarrow{\vec{n}}}$ surgery with radiotherapy aimed at preventing local recurrence is a rational mode of treatment in view of the present state of knowledge of this disease.

C. L. Berry is the Gilson scholar of the Worshipful Society of Apothecaries of London.

We should like to thank the Photographic Department of the Hospital for Sick Children for Figures 1-4.

\section{References}

Atwell, J. D., Claireaux, A. E., and Nixon, H. H. (1967). Teratoma 윽 of the stomach in the newborn. J. pediat. Surg., 2, 197-204. -

Bailey, R. J., Jr., Burgert, E. O., Jr., and Dahlin, D. C. (1961). C Malignant lymphoma in children. Pediatrics., 28, 985-992 $\mathbb{D}$

Berry, C. L., Keeling, J., and Hilton, C. (1969). Teratomata in infancy and childhood: a review of 91 cases. J. Path., 98, $\frac{\mathbb{D}}{2}$ 241-252.

Charache, H. (1956). Lymphosarcoma in infancy and childhood: including a case of twenty-two years' survival. Amer. $J . ~-~$ Roentgenol., 76, 594-598.

Cutler, G. D., Stark, R. B., and Scott, H. W. (1945). Lymphosarcoma of the bowel in childhood. New Engl.J. Med., 232,. 665-670.

Jones, B., and Klingberg, W. G. (1963). Lymphosarcoma in children. A report of 43 cases and review of the recent literature. J. Pediat., 63, 11-20.

Maxwell, G. M. (1954). Twelve cases of lymphoblastomata in children. Arch. Dis. Childh., 29, 155-159.

Mestel, A. L. (1959). Lymphosarcoma of the small intestine in $\mathbb{D}$ infancy and childhood. Ann. Surg., 149, 87-94.

Rigby, P. G., Rosenlof, R. C., Pratt, P. T., and Lemon, H. M. (1966). Leukemia and lymphoma. J. Amer. med. Ass., 197, 25-30.

Rosenberg, S. A., Diamond, H. D., Dargeon, H. W., and Craver, L. F. (1958). Lymphosarcoma in childhood. New Engl. J. Med., 259, 505-512.

Sullivan, M. P. (1962). Leukemic transformation in lympho- $\bar{O}$ sarcoma of childhood. Pediatrics, 29, 589-599.

\section{Addendum}

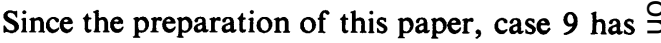
died, eight months after diagnosis. 